\title{
Al-10Si-xMg Alaşımının CALPHAD Metodolojisi ile Termodinamik Karakterizasyonu
}

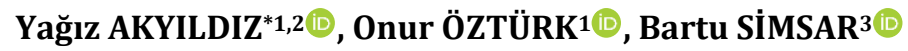 \\ ${ }^{1}$ Onatus Öngörü Teknolojileri, 41400, Kocaeli, Türkiye \\ ${ }^{2}$ Kocaeli Üniversitesi, Mühendislik Fakültesi, Metalurji ve Malzeme Mühendisliği Bölümü, 41380, Kocaeli, Türkiye \\ ${ }^{3}$ Ege Üniversitesi, Mühendislik Fakültesi, Makine Mühendisliği Bölümü, 35040, İzmir, Türkiye
}

\section{Anahtar Kelimeler}

Alüminyum,

CALPHAD Metodolojisi,

Thermo-Calc,

Al-Si-Mg Alaşımları,

Isıl İşlem

\begin{abstract}
Özet: Alüminyum ve alaşımları düşük yoğunluk, yüksek spesifik mukavemet, korozyon dayanımı, yüksek elektriksel ve ısıl iletkenlik özelliklerinden dolayı otomotiv, havacıllk ve uzay, savunma sanayilerinde yaygın olarak kullanılmaktadırlar. Genellikle malzemelerin mukavemetlerinin artırılması bakımından, alüminyum alaşımlarında isıl işlem ve deformasyon prosesleri uygulanmaktadır. Magnezyum ve bakır alaşım elementlerinin ilavesi ile alüminyum alaşımlarında kayda değer bir mukavemet artışı sağlanabilmektedir. Malzemelerin özellikleri; malzemelerin kimyasal kompozisyonlarına, proseslerine ve mikroyapılarına bağlı olarak değişmektedir. Bu modelleme ve simülasyon çalışmasında, Al-10Si-xMg alaşımında değişen \% ağırlıkça Mg oranlarının malzeme üzerindeki etkisi incelenmiş ve CALPHAD metodolojisinin kullanımı ile termodinamik analizleri gerçekleștirilmiştir. Modelleme ve simülasyon çalışmalarında Thermo-Calc yazılımı 2021a versiyonundaki TCAL7.1 alüminyum veri tabanı kullanılmıştır. Al-10Si-xMg alaşımında değişen \% ağırlıkça Mg oranının liküdüs, solidüs ve Al-Si alaşımlarında görülen ötektik reaksiyon sıcaklıklarına etkisi incelenmiştir. Ayrıca ısıl işlem ile mukavemet artışı sağlayan $\mathrm{Mg}_{2} \mathrm{Si}$ çökeltilerinin oluşum sıcaklıkları ve miktarları belirlenerek Türkçe literatüre katkı sağlanması düşünülmüştür.
\end{abstract}

\section{Thermodynamic Characterization of Al-10Si-xMg Alloy with CALPHAD Methodology}

\section{Keywords}

Aluminum,

CALPHAD Methodology,

Thermo-Calc,

Al-Si-Mg Alloy,

Heat Treatment

\begin{abstract}
Aluminum and its alloys are widely used in the automotive, aerospace space, and defence industries due to their low density, high specific strength, corrosion resistance, high electrical and thermal conductivity properties. Generally, heat treatment and deformation processes are applied in aluminum alloys in order to increase the strength of the materials. A significant increase in strength can be achieved in aluminum alloys with the addition of magnesium and copper as alloying elements. The properties of the materials vary depending on their chemical compositions, processes, and microstructures. In this modeling and simulation study, the effect of varying wt.\% Mg ratios in Al-10Si-xMg alloy on the material was investigated and thermodynamic analyzes were carried out using the CALPHAD methodology. TCAL7.1 aluminum database in the Thermo-Calc software version 2021a was used in the modelling and simulation studies. The effect of varying wt.\% $\mathrm{Mg}$ ratio in Al-10Si-xMg alloy on liquidus, solidus, and eutectic reaction temperatures observed in Al-Si alloys was investigated. In addition, it is thought to contribute to the Turkish literature by determining the formation temperatures and amounts of $\mathrm{Mg}_{2} \mathrm{Si}$ precipitates, which increase strength with heat treatment.
\end{abstract}

\section{Giriş}

Alüminyum ve alaşımları düşük yoğunluk, yüksek spesifik mukavemet, korozyon dayanımı, geri dönüşümü, yüksek elektriksel ve ısı iletimi, deformasyon ve isıl işlemle mukavemet artışı gibi özellikleri nedeniyle otomotiv, havacıllk ve uzay, savunma, gıda, enerji sektöründe yaygın olarak kullanılmaktadır [1-5]. Yüksek akıcılık, yüksek korozyon dayanımı, kaynaklanabilirlik, mukavemet artışı, dar katılaşma aralı̆̆ına sahip olma gibi özelliklerinden dolayı alüminyum alaşımları 
içerisinde Al-10Si-Mg ve Al-7Si-Mg gibi hipo-ötektik Al-Si-Mg alaşımları dikkat çekmektedir [6-8]. Magnezyum ve bakırın alüminyum alaşımlarına ilave edilmesi durumunda, çökelti sertleșmesi ısıl ișlemi ile $\mathrm{Mg}_{2} \mathrm{Si}$ ve $\mathrm{Al}_{2} \mathrm{Cu}$ gibi çökeltiler oluşturarak alüminyum alaşımlarında mukavemet artışı sağlanmaktadır [911]. Alüminyum alaşımlarında çökelti sertleşmesi prosesi üç aşamada gerçekleşmektedir. Bu aşamalar çözeltiye alma, su verme ve yaşlandırma adımlarını içermektedir [12].

Çökelti sertleşmesi prosesinde, alüminyum döküm alaşımlarında oluşan kaba $\alpha$-Al tane sınırlarında bulunan sürekli formdaki çökeltilerin oluşum sıcaklığının üzerindeki bir sıcaklıkta çözeltiye alarak, alüminyum yüzey merkezli kübik yapı içerisinde çözünmesi ile birlikte homojen bir yapı oluşturulur. $\mathrm{Bu}$ işlem genellikle yüksek sıcaklıkta difüzyon ile gerçekleștirilerek yüzey merkezli kübik alüminyum kristali içerisinde $\mathrm{Cu}, \mathrm{Mg}$ gibi alaşım elementlerinin çözünmesi durumunda çözeltiye alma ısıl işlemi ile başlamaktadır [13-15]. Yüzey merkezli kübik yapıda yüksek sıcaklık ve difüzyon ile homojen bir yapı oluşturulduktan sonra, su verme işlemi gerçekleştirilir. Sıcaklığın ani düşürülmesi ile birlikte difüzyon engellenerek yüksek sıcaklıktaki homojen, yüzey merkezli kübik yapı korunmuş olur. Çözeltiye alma ve su verme işlemi ile aşırı doymuş $\alpha$-Al tanelerinin solvüs eğrisi altındaki bir sıcaklıkta belirli bir süre tutulması ile birlikte $\mathrm{Cu}$ ve $\mathrm{Mg}$ atomlarının difüzyonuna izin verilmiş olur. $\mathrm{Bu}$ sayede $\mathrm{Al}_{2} \mathrm{Cu}$ ve $\mathrm{Mg}_{2} \mathrm{Si}$ gibi çökeltiler oluşturularak malzemede mukavemet artışı sağlanır [16]. Yapı içerisinde oluşturulan çökeltilerin boyutu ve dağılımı, malzemenin mukavemetini etkilemektedir. Alüminyum alașımlarında bu isıl ișlem prosesi yaygın olarak kullanılmaktadır. Isıl işlem prosesleri malzemelerin kimyasal kompozisyonuna göre belirlenirken, termodinamik ve termokinetik modellemeler yaygın olarak kullanılmaktadır $[17,18]$. Güvenilir termodinamik ve termokinetik veriler CALPHAD metodolojisi ile sağlanarak gerekli alaşım ve proses tasarımları gerçekleştirilebilmektedir.

Malzemelerin özellikleri kimyasal kompozisyon, proses ve mikroyapılarına bağlı olarak değişmektedir. Ar-Ge ve Ür-Ge çalışmalarında ilk olarak malzemelerin kimyasal kompozisyonu belirlenmektedir. Malzemelerin kimyasal kompozisyonu ve proseslerinin belirlenmesi durumunda nihai olarak mikroyapıları hakkındaki öngörüler çeşitli CALPHAD ve sonlu elemanlar metotları ile modellemesimülasyon çalışmaları yapılarak çeşitli malzeme özellikleri belirlenmektedir $[19,20]$. CALPHAD metodolojisi, alaşımların kimyasal kompozisyonuna göre mikroyapı ve üretim proses parametrelerinin belirlenmesinde güvenilir termodinamik veriler sağlamaktadır. Termodinamik veriler kullanılarak; kararlı ve yarı kararlı fazları, faz bileşenleri ve miktarı, kritik dönüşüm sıcaklıkları, Scheil-Gulliver yaklaşımı ile denge dışı katılaşma analizi gibi hesaplamalar sonucunda alaşımlar hakkında çeşitli veriler elde edilmektedir. Malzemeleri oluşturan fazlar, karbürler, çökeltiler, intermetalikler ve oluşum sıcaklıkları hakkında elde edilen veriler ile üretim, șekillendirme ve isıl işlem proses sicaklıkları belirlenerek proses dizaynları yapılmaktadır [21-23].

$\mathrm{Bu}$ modelleme ve simülasyon çalışmasında CALPHAD metodolojisi kullanılarak farklı oranda $\mathrm{Mg}$ içeren $\mathrm{Al}-$ 10Si-xMg alaşımları ( $\mathrm{x}=0.2,0.4,0.6 \%$ ağırlıkça) incelenmiştir. İlk olarak Al-Si ikili denge sisteminin analizi yapılmıștır. Daha sonra $\mathrm{Al}-\mathrm{Si}$ alaşımına $\mathrm{Mg}$ ilavesi ile birlikte alaşımı oluşturan $\alpha$-Al, ötektik silisyum ve $\mathrm{Mg}_{2} \mathrm{Si}$ fazları ve bu fazların oda sıcaklığındaki dağılımları hesaplanmıştır. $\mathrm{Bu}$ faz bölgelerini birbirinden ayıran liküdüs, solidüs, ötektik reaksiyon ve çökeltilerin meydana geldiği kritik dönüşüm sıcaklıkları belirlenmiștir. Böylece endüstriyel olarak yaygın kullanılan $\mathrm{Al}-10 \mathrm{Si}-\mathrm{xMg}$ alaşımlarında Mg oranının üretim, şekillendirme ve ısıl işlem sıcaklıkları gibi kritik sıcaklıkları nasıl etkilediği incelenerek literatüre katkı sağlanacağı düşünülmektedir.

\section{Materyal ve Metot}

Modelleme ve simülasyon çalışmalarında ThermoCalc yazılımı 2021a versiyonundaki TCAL7.1 termodinamik veri tabanı kullanılmıştır. Termodinamik modelleme süreçlerinde, alaşımların kimyasal kompozisyonlarından yola çlkarak Gibbs Serbest Enerji denklemine göre çözüm yapılmaktadır. Gibbs Serbest Enerjisi'ni etkileyen üç ana bileșen vardır. Bunlar sıcaklık, basınç ve kimyasal kompozisyondur. Parametrelerin etkileşimleri sonucunda, Gibbs Serbest Enerjisi minimizasyonu ile faz bölgeleri oluşturulmaktadır. Endüstriyel olarak yapılan deneysel çalışmalar sabit sıcaklık ve basınç altında yapılmaktadır. Dolayısıyla Gibbs Serbest Enerjisi'ni minimize etmenin yolu kimyasal kompozisyon değişimleri ile meydana gelmektedir. Alaşımların çok bileşenli sistemlerinde, Gibbs Serbest Enerjisi'nin minimizasyonunda, Denklem 1'de verilen formül kullanılmaktadır. Denkleme göre elementlerin referans durumları $\left(\mathrm{Gm}^{0}\right)$, karıșım durumundaki enerjileri $\left(\mathrm{G}_{\mathrm{m}}\right.$ ideal $)$ ve ikili, üçlü, dörtlü gibi çoklu etkileşimlerindeki $\left(\mathrm{Gm}^{\mathrm{xs}}\right)$ enerjilerin toplamı sistemin çözelti durumundaki mol başına Gibbs Serbest Enerjisi'ni vermektedir $[24,25]$.

$$
G_{m}=G_{m}^{0}+G_{m}^{i d e a l}+G_{m}^{x s}
$$

CALPHAD metodolojisinin kullanımı ile Thermo-Calc yazılımının 2021a versiyonunda gerçekleştirilen modelleme ve simülasyon çalışması çerçevesinde, Al10Si-xMg ( $\mathrm{x}=0.2,0.4,0.6 \%$ ağırlıkça) alaşımlarının termodinamik karakterizasyonları yapılmıştır. Gibbs Serbest Enerjisi denkleminin kullanımına dayalı olarak gerçekleştirilen bu termodinamik karakterizasyon ile birlikte; $\mathrm{Al}-10 \mathrm{Si}-\mathrm{xMg}$ alaşımlarında liküdüs, solidüs ve ötektik dönüşüm 
aralıkları, $\mathrm{Mg}_{2} \mathrm{Si}$ intermetaliğinin çökelmeye başlama sıcaklıkları ve yapıdaki hacimce faz oranları hesaplanmıştır. Analiz çıtıllarının yorumlanması ile Al-10Si alaşımına ilave edilen \% ağırlıkça $0.2,0.4$ ve 0.6 Mg'nin, yukarıda bahsedilen faz ve faz miktarları ile kritik dönüşüm sıcaklıklarına olan etkileri değerlendirilmiş ve bu veriler Türkçe literatüre kazandırılmıştır.

\section{Bulgular}

Thermo-Calc yazılımı 2021a versiyonunda TCAL7.1 veri tabanı ile Şekil 1'de verilen Al-Si ikili denge diyagramı hesaplanmıștır. Al-Si alaşımı $577^{\circ} \mathrm{C}$ 'de yaklaşık \% ağırlıkça 12 Si oranında ötektik reaksiyona sahiptir. Ötektik reaksiyon ile ergiyik, $\alpha$-Al ve ötektik silisyuma dönüşmektedir. Silisyum oranına bağlı olarak Al-Si alaşımları hipo-ötektik, ötektik ve hiperötektik olarak gruplandırılmaktadır. Bu modelleme ve simülasyon çalışmasında \% ağırlıkça $10 \mathrm{Si}$ içeren Al$10 \mathrm{Si}$-xMg alaşımı üzerine yoğunlaşılmıștır. Alașımın katılașma durumuna göre ergiyikten ilk katılașan faz $\alpha$-Al'dur. Daha sonra sıcaklığın düşmesi ile ötektik reaksiyon meydana gelerek, ergiyik faz iki ayrı faza dönüşmektedir. Al-Si alaşımlarına $\mathrm{Mg}$ ilavesi ile birlikte katı fazdan $\mathrm{Mg}_{2} \mathrm{Si}$ çökelmektedir.

Şekil 1'de verilen Al-Si ikili denge diyagramında \% ağırlıkça 10 Si içeren noktadan yapılan termodinamik hesaplamalar sonucunda katılaşma analizi Şekil 2'deki gibi hesaplanmıştır. Saf alüminyum içerisine ilave edilen \% ağırlıkça 10 Si ile ergime sıcaklığ $65^{\circ} \mathrm{C}$ 'lik bir azalma ile $595^{\circ} \mathrm{C}^{\prime}$ ye düșmüștür. Şekil 1'de verilen Al-Si ikili denge diyagramında da ötektik noktaya kadar artan \% ağırlıkça $\mathrm{Si}$ oranı ile birlikte ergime sıcaklıkları $577^{\circ} \mathrm{C}^{\prime}$ lere kadar düşebilmektedir. Al-Si ikili denge sisteminde $577^{\circ} \mathrm{C}$ 'de meydana gelen ötektik reaksiyon ile ergiyik, $\alpha$-Al ve ötektik silisyuma dönüşmektedir. Al-10Si alaşımı oda sıcaklığında $\alpha$-Al ve ötektik silisyum fazlarından oluşmakta ve hacimce $\% 11$ ötektik Si ve $\% 89 \alpha-A l$ içermektedir.



Şekil 1. Al-Si ikili denge diyagramı

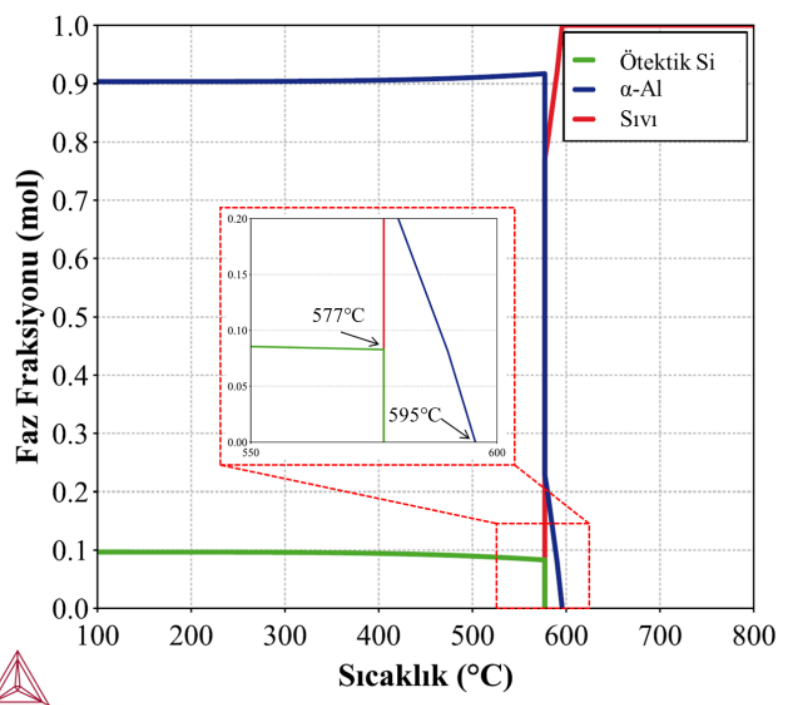

Şekil 2. Al-10Si alaşımının sıcaklığa bağlı faz fraksiyonu

Al-10Si-0.2Mg alaşımının termodinamik karakterizasyonu sonucunda Şekil 3'de verilen sıcaklığa bağlı faz fraksiyonu diyagramı hesaplanmıștır. Alașımın $23^{\circ} \mathrm{C}^{\prime}$ lik bir katılașma aralığına sahip olduğu görülmektedir. Hipo-ötektik Al$10 \mathrm{Si}-0.2 \mathrm{Mg}$ alaşımında $595^{\circ} \mathrm{C}$ 'de $\alpha$-Al katılaşmaya başlamaktadır. Çok bileșenli sistemlerde görülen çeşitli faz reaksiyonları, izoplet faz diyagramlarında alana dönüşmektedir. Dolayısıyla ergiyikten, $\alpha$-Al ve ötektik silisyum dönüşümü $576-572^{\circ} \mathrm{C}$ arasında meydana gelmektedir. \% ağırlıkça $0.2 \mathrm{Mg}$ içeren alaşım $4^{\circ} \mathrm{C}$ 'lik bir ötektik reaksiyon aralığına sahiptir. $\mathrm{Mg}$ ve $\mathrm{Si}$ alaşım elementleri arasında 2:1 stokiyometrik oranlı $\mathrm{Mg}_{2} \mathrm{Si} \quad 420^{\circ} \mathrm{C}$ çökelmeye başlamaktadır. Termodinamik analiz sonucunda Al10Si-0.2Mg alaşımının oda sıcaklığında hacimce \%11 ötektik Si, \%88.5 $\alpha$-Al ve \%0.5 Mg2Si içermektedir.



Şekil 3. Al-10Si-0.2Mg alaşımının sıcaklığa bağlı faz fraksiyonu

Al-10Si-0.4Mg alaşımının termodinamik karakterizasyonu ile elde edilen sıcaklığa bağlı faz fraksiyon diyagramı Şekil 4'de verilmiştir. \% ağırlıkça $0.4 \mathrm{Mg}$ ilavesi ile alaşım $27^{\circ} \mathrm{C}$ 'lik bir katılaşma aralığı 
ile katılaşmaktadır. $594^{\circ} \mathrm{C}^{\prime} \mathrm{de} \mathrm{Al}-10 \mathrm{Si}-0.4 \mathrm{Mg}$ hipoötektik alaşım $\alpha$-Al fazı ile katılaşmaya başlamaktadır. $575-567^{\circ} \mathrm{C}$ arasında $8^{\circ} \mathrm{C}$ 'lik bir ötektik reaksiyon ile $\alpha$ Al ve ötektik silisyum oluşmaktadır. Mg oranının \% ağırlıkça 0.2 'den 0.4 'e çıkması ile birlikte katılaşma ve ötektik reaksiyon aralığında bir artış meydana gelirken, $420^{\circ} \mathrm{C}^{\prime}$ de çökelen $\mathrm{Mg}_{2} \mathrm{Si}$ intermetaliği $487^{\circ} \mathrm{C}$ 'de çökelmeye başlamaktadır. Katılaşma ile birlikte Al-10Si-0.4Mg alaşımı oda sıcaklığında hacimce \%11 ötektik Si, \%88.1 $\alpha$-Al ve $\% 0.9 \mathrm{Mg}_{2} \mathrm{Si}$ fazlarını içermektedir.

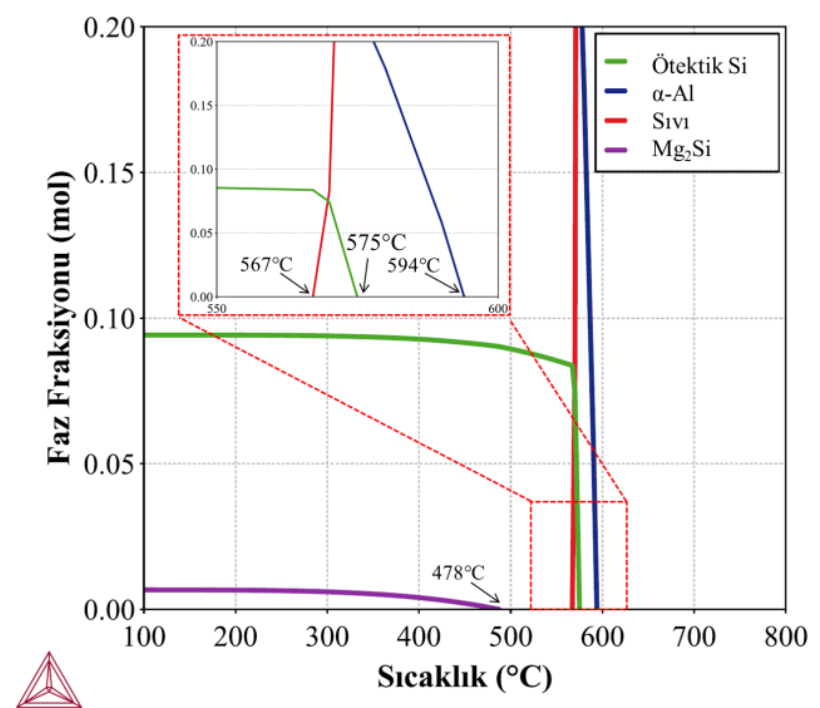

Şekil 4. Al-10Si-0.4Mg alaşımının sıcaklığa bağlı faz fraksiyonu

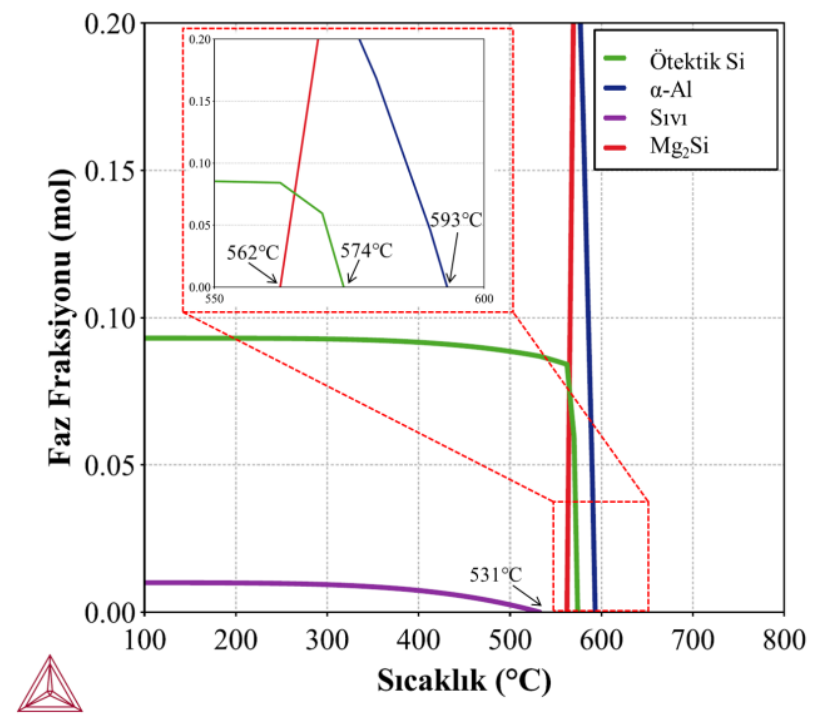

Şekil 5. Al-10Si-0.6Mg alașımının sıcaklığa bağlı faz fraksiyonu

Alaşım içerisindeki Mg oranının \% ağırlıkça 0.6 olması ile elde edilen faz fraksiyonu diyagramı Şekil 5'de verilmiștir. Ergiyikten ilk katılaşan $\alpha$-Al fazı $593^{\circ} \mathrm{C}$ 'de görülmektedir. Al-10Si-0.6Mg alaşımda meydana gelen ötektik reaksiyon ile ergiyik fazın, ötektik silisyum ve $\alpha$-Al fazına dönüşmesi $12^{\circ} \mathrm{C}^{\prime}$ lik sıcaklık aralığı ile $574-562^{\circ} \mathrm{C}^{\prime}$ leri arasında meydana gelmektedir. Alaşım $562^{\circ} \mathrm{C}^{\prime}$ de katılaşmasını $31^{\circ} \mathrm{C}$ 'lik bir katılaşma aralığı ile tamamlamaktadır. Mg oranın
\% ağırlıkça 0.6 olması ile birlikte katı faz içerisinden çökelen $\mathrm{Mg}_{2} \mathrm{Si}$ çökeltileri $531^{\circ} \mathrm{C}$ 'de oluşmaktadır. Alaşım içerisindeki Mg oranının \% ağırlıkça 0.6 olması ile birlikte oda sıcaklığındaki hacimce faz oranı \%11 ötektik Si, \%88 $\alpha$-Al ve $\% 1 \mathrm{Mg}_{2}$ Si'dir.

\section{Tartışma ve Sonuç}

Endüstriyel uygulamalarda yaygın olarak kullanılan Al-10Si-X-Mg alaşımında Mg oranının değişmesi termodinamik olarak CALPHAD metodolojisi ile analiz edilmiştir. Termodinamik analizler Thermo-Calc yazılımı 2021a versiyonu TCAL7.1 veri tabanı kullanılarak yapılmıştır. Al-10Si alaşımına ilave edilen \% ă̆ırlıkça $0.2,0.4$ ve $0.6 \mathrm{Mg}$ ilavesinin faz ve faz miktarına, kritik dönüşüm sıcaklıklarına etkisi incelenmiştir. Modelleme ve simülasyon çalışmaları ile Al-Si-Mg alaşımlarının kritik dönüşüm sıcaklıkları ile Türkçe literatüre katkı sağlanmıştır. İnceleme sonuçlarına göre:

- Mg oranının artması ile birlikte alaşımın ergime sıcaklığında $1^{\circ} \mathrm{C}$ 'lik azalmalar meydana gelmiştir.

- $\quad \mathrm{Al}-10 \mathrm{Si}$ alaşımı katılaşmasını $595-577^{\circ} \mathrm{C}$ arasında $18^{\circ} \mathrm{C}$ 'lik bir aralıkta tamamlarken, Mg oranının artması ile alaşımın katılaşma aralığı sırasıyla 23, 27 ve $31^{\circ} \mathrm{C}$ olarak hesaplanmıştır. Dolayısıyla alaşıma ilave edilen Mg oranı ile birlikte katılaşma sıcaklık aralığı artmaktadır.

- Alüminyum ve silisyumdan oluşan ikili alaşım sisteminde ötektik reaksiyon $577^{\circ} \mathrm{C}^{\prime} \mathrm{de}$ tamamlanmaktadır. Fakat alaşım içerisine ilave edilen Mg ile birlikte ötektik reaksiyon belli bir sıcaklık aralığında tamamlanmaktadır. Mg oranının artması ile birlikte ötektik reaksiyon sirasıyla $\quad 4, \quad 8$ ve $12^{\circ} \mathrm{C}^{\prime}$ lik aralıkta tamamlamaktadır. Böylece Mg oranının artması ile birlikte ergiyiğin, $\alpha$-Al ve ötektik silisyuma dönüşüm aralığı artmaktadır.

- $\quad$ Al-Si-Mg sistemlerinde Mg ve Si'nin oluşturduğu $\mathrm{Mg}_{2} \mathrm{Si}$ çökeltisi ile mekanik özelliklerde artış meydana gelir. Alüminyum ısıl işleminde çözeltiye alma ile $\mathrm{Mg}_{2} \mathrm{Si}$ çökeltisini alüminyumun yüzey merkezli kübik sisteminde çözme işlemi başlar. Mg oranının artması ile birlikte sırasıyla Al-10SixMg alaşımının minimum çözeltiye alma sicaklıkları 420,487 ve $531^{\circ} \mathrm{C}$ olarak belirlenmiștir.

- Mg oranının artması ile birlikte alaşım içerisinde çökelen $\mathrm{Mg}_{2} \mathrm{Si}$ intermetaliğinin hacimce miktarı sırasıyla $0.5,0.9$ ve 1 olarak hesaplanmıștır.

\section{Etik Beyanı}

Bu çalışmada, "Yükseköğretim Kurumları Bilimsel Araștırma ve Yayın Etiği Yönergesi" kapsamında uyulması gerekli tüm kurallara uyulduğunu, bahsi 
geçen yönergenin "Bilimsel Araştırma ve Yayın Etiğine Aykırı Eylemler" başlı̆̆ı altında belirtilen eylemlerden hiçbirinin gerçekleştirilmediğini taahhüt ederiz.

\section{Kaynakça}

[1] Ahn, C., Jo, I., Ji, C., Cho, S., Mishra, B., Lee, E. 2020. Creep behavior of high-pressure die-cast AlSi10MnMg aluminum alloy. Materials Characterization, 167, 110495.

[2] Babaremu, K. O., Joseph, O. O., Akinlabi, E. T., Jen, T. C., Oladijo, O. P. 2020. Morphological investigation and mechanical behaviour of agrowaste reinforced aluminium alloy 8011 for service life improvement. Heliyon, 6(11), e05506.

[3] Georgantzia, E., Gkantou, M., Kamaris, G. S. 2021. Aluminium alloys as structural material: A review of research. Engineering Structures, 227, 111372.

[4] Vijayakumar, M., Dhinakaran, V., Sathish, T., Muthu, G. 2021. Experimental study of chemical composition of aluminium alloys. Materials Today: Proceedings, 37, 1790-1793.

[5] Yamanoğlu, R., Karakulak, E., Zeren, A., Zeren, M. 2013. Effect of heat treatment on the tribological properties of $\mathrm{Al}-\mathrm{Cu}-\mathrm{Mg} /$ nanoSiC composites. Materials \& Design, 49, 820-825.

[6] Hadadzadeh, A., Amirkhiz, B. S., Shakerin, S., Kelly, J., Li, J., Mohammadi, M. 2020. Microstructural investigation and mechanical behavior of a two-material component fabricated through selective laser melting of AlSi10Mg on an $\mathrm{Al}-\mathrm{Cu}-\mathrm{Ni}-\mathrm{Fe}-\mathrm{Mg}$ cast alloy substrate. Additive Manufacturing, 31, 100937.

[7] Rafieazad, M., Mohammadi, M., Gerlich, A., Nasiri, A. 2021. Enhancing the corrosion properties of additively manufactured $\mathrm{AlSi} 10 \mathrm{Mg}$ using friction stir processing. Corrosion Science, 178, 109073.

[8] Wei, P., Chen, Z., Zhang, S., Fang, X., Lu, B., Zhang, L., Wei, Z. 2021. Effect of T6 heat treatment on the surface tribological and corrosion properties of AlSi10Mg samples produced by selective laser melting. Materials Characterization, 171, 110769.

[9] Gao, Y. H., Kuang, J., Zhang, J. Y., Liu, G., Sun, J. 2020. Tailoring precipitation strategy to optimize microstructural evolution, aging hardening and creep resistance in an $\mathrm{Al}-\mathrm{Cu}-\mathrm{Sc}$ alloy by isochronal aging. Materials Science and Engineering, A 795, 139943.

[10] Karakulak, E., Zeren, M., Yamanoğlu, R. 2013. Effect of heat treatment conditions on microstructure and wear behaviour of Al4Cu2Ni2Mg alloy. Transactions of Nonferrous Metals Society of China, 23(7), 1898-1904.
[11] Kuchariková, L., Tillová, E., Chalupová, M., Hanusová, P. 2020. Investigation on microstructural and hardness evaluation in heattreated and as-cast state of secondary AlSiMg cast alloys. Materials Today: Proceedings, 32, 63-67.

[12] Chou, C.-Y., Hsu, C.-W., Lee, S.-L., Wang K.-W., Lin, J.-C. 2008. Effects of heat treatments on AA6061 aluminum alloy deformed by cross-channel extrusion. Journal of materials processing technology, 202(1-3), 1-6.

[13] Wu, Y., Xiong, J., Lai, R., Zhang, X., Guo, Z. 2009. The microstructure evolution of an $\mathrm{Al}-\mathrm{Mg}-\mathrm{Si}-$ $\mathrm{Mn}-\mathrm{Cu}-\mathrm{Ce}$ alloy during homogenization. Journal of Alloys and Compounds, 475(1-2), 332-338.

[14] Yan, L.-Z., Zhang, Y.-A., Li, X.-W., Li, Z.-H., Feng, W., Liu, H.-W., Xiong, B.-Q. 2014. Microstructural evolution of Al-0.66 Mg-0.85 $\mathrm{Si}$ alloy during homogenization. Transactions of Nonferrous Metals Society of China, 24(4), 939-945.

[15] Yang, H., Ji, S., Yang, W., Wang, Y., Fan, Z. 2015. Effect of $\mathrm{Mg}$ level on the microstructure and mechanical properties of die-cast $\mathrm{Al}-\mathrm{Si}-\mathrm{Cu}$ alloys. Materials Science and Engineering, A 642, 340350.

[16] Dons, A. L. 2001. The Alstruc homogenization model for industrial aluminum alloys. Journal of light Metals, 1(2), 133-149.

[17] Milkereit, B., Froeck, H., Schick, C., Kessler, O. 2014. Continuous cooling precipitation diagram of cast aluminium alloy Al-7Si-0.3Mg. Transactions of Nonferrous Metals Society of China, 24(7), 2025-2033.

[18] Sjölander, E., Seifeddine, S. 2010. The heat treatment of $\mathrm{Al}-\mathrm{Si}-\mathrm{Cu}-\mathrm{Mg}$ casting alloys. Journal of Materials Processing Technology, 210(10), 1249-1259.

[19] Ågren, J. 1996. Calculation of phase diagrams: Calphad. Current opinion in solid state and materials science, 1(3), 355-360.

[20] Jha, R., Dulikravich, G. S. 2020. Solidification and heat treatment simulation for aluminum alloys with scandium addition through CALPHAD approach. Computational Materials Science, 182, 109749.

[21] Fabrichnaya, O., Saxena, S. K., Richet P., Westrum, E. F. 2004. Thermodynamic data, models, and phase diagrams in multicomponent oxide systems: An Assessment for Materials and Planetary Scientists Based on Calorimetric, Volumetric and Phase Equilibrium Data. Springer Science \& Business Media.

[22] Sieniutycz, S. 2016. Thermodynamic approaches in engineering systems. Elsevier. 738s.

[23] Yamanoğlu, R., Akyıldız, Y., Öztürk, O. 2021. AlSi10Mg Alaşımının Toz Metalurjisi ile Üretimi: 
Basınç Destekli Sinterleme ve Calphad Metodolojisi. International Symposium of Scientific Research and Innovative Studies, Bandırma Onyedi Eylül Üniversitesi.

[24] Liu, C., Shi, Q., Yan, W., Shen, C., Yang, K., Shan, Y., Zhao, M. 2019. Designing a high Si reduced activation ferritic/martensitic steel for nuclear power generation by using Calphad method. Journal of materials science \& technology, 35(3), 266-274.
[25] Pelton, A. D. 2018. Phase diagrams and thermodynamic modeling of solutions. Academic Press. 401s. 